\title{
The relationship between pain severity and patient-reported outcomes among patients with chronic low back pain in Japan
}

This article was published in the following Dove Press journal:

Journal of Pain Research

2 June 2016

Number of times this article has been viewed

\author{
William Montgomery' \\ Jeffrey Vietri \\ jing $\mathrm{Shi}^{3}$ \\ Kei Ogawa ${ }^{4}$ \\ Sawako Kariyasu ${ }^{4}$ \\ Levent Alev ${ }^{4}$ \\ Masaya Nakamura ${ }^{5}$
}

'Eli Lilly Australia Pty Ltd., Sydney, NSW, Australia; ${ }^{2} \mathrm{Health}$ Outcomes Practice, Kantar Health, Horsham, PA, ${ }^{3}$ Health Outcomes Practice, Kantar Health, Princeton, NJ, USA; ${ }^{4}$ Eli Lilly Japan K.K., Kobe, Japan; ${ }^{5}$ Department of Orthopedic Surgery, Keio University School of Medicine, Tokyo, Japan
Correspondence: Jeffrey Vietri Health Outcomes Practice, Kantar Health, 700 Horsham Road, Horsham, PA 19044, USA

Tel + I 9088873535

Fax +I 6099875514

Email Jeffrey.vietri@kantarhealth.com
Objective: The aim of this study was to quantify the impact of pain severity on patient-reported outcomes among individuals diagnosed with chronic low back pain in Japan.

Methods: Data were provided by the 2012 Japan National Health and Wellness Survey $(\mathrm{N}=29,997)$, a web-based survey of individuals in Japan aged $\geq 18$ years. This analysis included respondents diagnosed with low back pain of $\geq 3$-month duration. Measures included the revised Medical Outcomes Study 36-Item Short-Form Survey Instrument, the Patient Health Questionnaire-9, the Generalized Anxiety Disorder-7 scale, the Work Productivity and Activity Impairment: General Health questionnaire, and self-reported all-cause health care visits ( 6 months). Generalized linear models were used to assess the relationship between outcomes and severity of pain in the past week as reported on a numeric rating scale ranging from 0 (no pain) to 10 (pain as bad as you can imagine), controlling for length of diagnosis, sociodemographics, and general health characteristics. Results: A total of 290 respondents were included in the analysis; mean age was 56 years, $41 \%$ were females, and $56 \%$ were employed. Pain severity was $3 / 10$ for the first quartile, $5 / 10$ for the median, and 7/10 for the third quartile of this sample. Increasing severity was associated with lower scores for mental and physical component summaries and Short-Form 6D health utility, higher depression (Patient Health Questionnaire-9) and anxiety (Generalized Anxiety Disorder-7) scores, greater absenteeism and presenteeism, greater activity impairment, and more health care provider visits (all $P<0.0001$ ).

Conclusion: The impact of chronic low back pain on health-related quality of life, depression and anxiety symptoms, impairment to work and daily activities, and health care use increases with the severity of pain. Interventions reducing the severity of pain may improve numerous health outcomes even if the pain cannot be eliminated.

Keywords: work impairment, quality of life, chronic pain

\section{Introduction}

Effective management of chronic pain has become a crucial consideration in medical care due to its prevalence and far-ranging effects. ${ }^{1}$ Chronic pain is defined as pain that lasts for at least 3 months and is often associated with diseases such as cancer and diabetes, ${ }^{2}$ but may occur at any point across a patient's lifetime. ${ }^{3}$ In Japan, addressing chronic pain - particularly low back pain (LBP) - is becoming an important issue in medical care. LBP is a common condition in Japan and is the fifth most widely cited reason for outpatient medical visits. ${ }^{4} \mathrm{~A}$ recent study found that the prevalence of chronic musculoskeletal pain in Japan was $15.4 \%$, with the lower back being reported as one of the most common sites for pain. ${ }^{5}$ Another study assessing the societal burden of chronic pain in Japan also found that back pain was one of the most common pain 
types and was reported by more than half of the respondents with chronic pain. ${ }^{6}$

Chronic LBP (CLBP) can lead to severe activity impairment and physical limitations. ${ }^{7}$ In addition to its physical impact, various studies have found that individuals with CLBP also have significantly greater levels of depression, anxiety, and sleep impairment when compared with matched controls without CLBP. ${ }^{8}$ CLBP is also associated with higher use of health care services and greater work impairment. ${ }^{8,9}$ One study found that the total direct medical costs for those with CLBP were more than twice as high when compared with controls who did not have CLBP. ${ }^{8}$ Another study found that workers with back pain had work impairment levels between 1.54 and 1.77 times the levels of employees who had no back pain. ${ }^{10}$

In spite of its documented impact, CLBP has not been adequately studied in many populations. ${ }^{1}$ In particular, there is a dearth of literature exploring the relationship between the severity of CLBP and mental and physical health outcomes, health care costs, and work productivity of patients suffering from this condition in Japan. Research from Sweden has found that both medical costs and productivity losses were significantly correlated with severity of CLBP. ${ }^{11}$ Similar results have been found in research conducted in other countries. ${ }^{12,13}$ The relationship between increasing severity of pain and worse outcomes is not unique to CLBP but has been noted in other chronic pain conditions as well. For example, osteoarthritis and painful diabetic peripheral neuropathy demonstrate a similar relationship between increasing pain severity levels and poorer outcomes in terms of increased health care costs, greater impairment at work, and impairment in performing daily activities. ${ }^{13-15}$ Chronic pain conditions not only can have an adverse impact on daily lives of patients but can also affect the people around them, ${ }^{16}$ further underscoring the importance of effective management of chronic pain conditions, including CLBP. Identifying poorer outcomes at varying severity levels can inform the selection of appropriate management strategies and treatment options. ${ }^{7}$ This study was conducted to document the relationship between the severity of pain and a range of patient outcomes among Japanese patients with CLBP. Outcomes of interest included health-related quality of life (HRQoL), depression and anxiety symptoms, work productivity, activity impairment, and health care resource use.

\section{Methods}

\section{Data source}

Data were provided by the 2012 Japan National Health and Wellness Survey (NHWS; Kantar Health, New York, NY, USA), an annual Internet-based survey of the general population aged 18 years and older in Japan. The NHWS was designed as a general health questionnaire and includes items regarding experience and diagnosis of a variety of health conditions, demographics, and several standard outcome measures, which are described in more detail in the following sections. Potential respondents were selected from an opt-in survey panel through stratified random sampling, with strata organized by age and sex that were specified to match the population. In addition to membership in the survey panel, respondents were required to read and write Japanese, be at least 18 years old, and provide informed consent. All information was collected through self-report. The protocol and questionnaire for the NHWS were reviewed and approved by Essex Institutional Review Board, Inc. (Lebanon, NJ, USA). This analysis was focused exclusively on respondents with CLBP, which is defined in the "Measures" section. The flow of respondents from sampling through inclusion in the analyses is depicted in Figure 1.

\section{Measures}

CLBP: Respondents were considered to have CLBP if they experienced LBP in the past month and had also been diagnosed by a physician with LBP for at least 3 months. Respondents who also reported pain due to broken bones, cancer, or surgery were excluded, as were respondents with other types of pain, which they rated as more severe than they rated their LBP on the 3-point scale mentioned in the following sections.

Pain severity: Severity of pain in the past week was reported on numeric rating scale (NRS) ranging from 0 (no pain) to 10 (pain as bad as you can imagine). Patients also rated the severity of their CLBP as well as other types of pain on a 3-point scale as mild, moderate, or severe, separately for each type of pain.

HRQoL: The revised Medical Outcomes Study 36-Item Short-Form Survey Instrument (SF-36v2) was used to measure the HRQoL. ${ }^{17}$ This is a multipurpose, generic HRQoL instrument. Two summary scores calculated from this measure were used: the physical component summary (PCS), an index of overall physical functioning, and the mental component summary (MCS) scores, which is an index of mental and emotional health. Scores can be interpreted relative to the US population average of 50 with a standard deviation of 10 , with higher scores indicating better HRQoL.

Responses to the SF-36v2 were also used to generate health state utilities according to the Short-Form 6D (SF-6D) algorithm, a preference-based, single index measure for health using general population values. ${ }^{18}$ The SF-6D index has interval scoring properties and yields summary scores on a theoretical 0-1 scale (with an empirical floor of 0.3 ). 


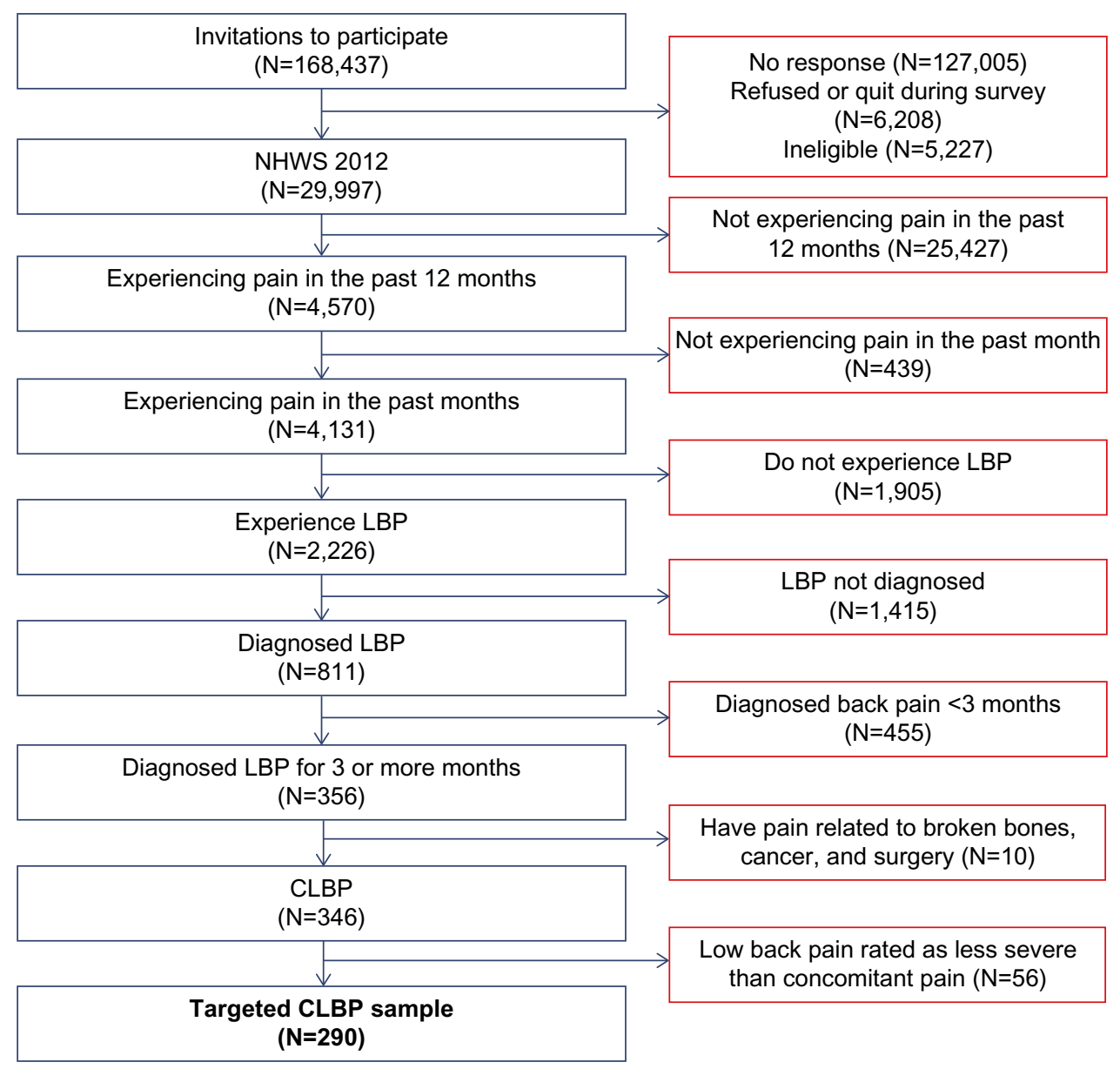

Figure I Selection of respondents for the analysis.

Abbreviations: CLBP, chronic low back pain; LBP, low back pain; NHWS, National Health and Wellness Survey.

Higher scores indicate better (more preferred) health status, with 1 being equivalent to perfect health.

Depression symptoms: Depression symptoms/severity of depression over the last 2 weeks was assessed using the Patient Health Questionnaire-9, ${ }^{19}$ a validated scale used to screen for depression and to assess its severity. The total scale score was calculated, and the severity of depression was assigned according to the standard cutoff categories: minimal (0-4), mild (5-9), moderate (10-14), moderately severe (15-19), and severe (20 or greater).

Anxiety symptoms: Symptoms of anxiety were measured using the Generalized Anxiety Disorder- 7 scale. ${ }^{20}$ The total score was analyzed both as a continuous measure and according to the standard categories: minimal (0-4), mild (5-9), moderate (10-14), and severe (15 or greater).

Work productivity and activity impairment: Work productivity was assessed using the general health version of the Work Productivity and Activity Impairment questionnaire, which assesses absenteeism (work time missed), presenteeism (impairment while at work), overall work productivity impairment (a combination of absenteeism and presenteeism), and activity impairment (impairment in daily activities) due to health problems over the prior 7 days. ${ }^{21}$ All are reported as percentages, with higher numbers indicating greater impairment. Only respondents who reported being employed full-time, part-time, or self-employed provided data for absenteeism, presenteeism, and overall work impairment. All respondents provided data for activity impairment.

Health care resource use: Health care resource use was assessed in the NHWS as all-cause health care provider (HCP) visits, emergency room (ER) visits, and hospitalizations in the 6 months prior to the survey. HCP visits were calculated by summing the self-reported number of visits to specific types of HCPs (eg, general internist, psychiatrist, allergist, dentist, and nurse).

\section{Statistical analysis}

Respondents who reported a physician diagnosis of CLBP were first described with univariate statistics. Bivariate Spearman correlations were then calculated to assess the strength of the relationship between severity of pain in the past week and health outcomes. A series of generalized linear 
models were conducted to assess the relationship between the severity and CLBP and outcomes while accounting for potential confounders. Because the rating of pain severity in the past week was modeled as a continuous variable, means at the first quartile, median, and the third quartile value of severity of pain in the past week were estimated to demonstrate outcomes associated with mild, moderate, and severe pain, respectively. An additional set of generalized linear models were conducted using self-ratings of CLBP as mild, moderate, or severe as dummy-coded categories to ensure the pattern of results was consistent using a rating of severity specific to LBP.

The specifications of the models varied based on the outcome being modeled. Health status and the SF-6D were modeled using linear models, while work productivity and activity impairment and health care visits were modeled using negative binomial distributions and log link functions. Covariates included duration of CLBP, age, sex, Charlson comorbidity index calculated from self-reported diagnoses, ${ }^{22}$ annual household income, marital status, completion of a university degree, body mass index category, smoking status, alcohol use, and exercise in the prior month.

Analyses were conducted in SAS Version 9.3. An alpha error level of 5\% (two-tailed) was used for all significance tests.

\section{Results}

\section{Sample characteristics}

A total of 29,997 individuals completed the NHWS. Of these, 25,427 indicated they were not experiencing pain. Of the remaining 4,570 patients, 743 indicated a doctor diagnosis of LBP, with 356 indicating they experienced LBP for 3 or more months. Ten patients were excluded due to report of broken bones, cancer, or surgery as a source of comorbid pain, and a further 56 for having concomitant painful conditions with more severe pain than their LBP, resulting in 290 patients with CLBP included in this analysis.

Demographic and general health characteristics are presented in Table 1. The sample had a mean age of 56 years; $41 \%$ were females and $56 \%$ were employed. Information on patients' pain is presented in Table 2. Most of the sample rated their LBP as moderate (56\%), and the average severity of pain on the NRS was 4.9 out of 10; the 25th, 50th (median), and 75 th percentile values for pain were $3 / 10,5 / 10$, and $7 / 10$, respectively.

The great majority of respondents had been diagnosed by an orthopedist ( $85 \%$ ), and $41 \%$ were taking prescription
Table I Sociodemographic and health characteristics

\begin{tabular}{|c|c|}
\hline & $\begin{array}{l}\text { Diagnosed CLBP } \\
(\mathrm{N}=\mathbf{2 9 0})\end{array}$ \\
\hline Age (years) (mean $\pm S D)$ & $55.60 \pm \mid 4.58$ \\
\hline Female (\%) & I I 8 (40.69) \\
\hline $\mathrm{CCl}($ mean $\pm \mathrm{SD})$ & $0.46 \pm 0.95$ \\
\hline Employed (\%) & $161(55.52)$ \\
\hline \multicolumn{2}{|l|}{ Annual household income } \\
\hline$<¥ 3$ million (\%) & $48(16.55)$ \\
\hline$¥ 3$ million to $<¥ 5$ million (\%) & 81 (27.93) \\
\hline$¥ 5$ million to $<¥ 8$ million (\%) & $76(26.21)$ \\
\hline$¥ 8$ million or more $(\%)$ & $70(24.14)$ \\
\hline Decline to answer (\%) & $15(5.17)$ \\
\hline Married/living with partner (\%) & $211(72.76)$ \\
\hline University education or higher (\%) & I 40 (48.28) \\
\hline \multicolumn{2}{|l|}{ BMI category } \\
\hline Underweight (\%) & $21(7.24)$ \\
\hline Normal weight (\%) & $200(68.97)$ \\
\hline Overweight (\%) & $56(19.31)$ \\
\hline Obese (\%) & $9(3.10)$ \\
\hline Decline to provide weight (\%) & $4(1.38)$ \\
\hline \multicolumn{2}{|l|}{ Smoking } \\
\hline Never smoked (\%) & $107(36.90)$ \\
\hline Former smoker (\%) & $105(36.21)$ \\
\hline Current smoker (\%) & $78(26.90)$ \\
\hline Drink alcohol (\%) & $215(74.14)$ \\
\hline $\begin{array}{l}\text { Vigorous exercise at least I day in the } \\
\text { past month (\%) }\end{array}$ & $134(46.21)$ \\
\hline
\end{tabular}

Abbreviations: BMI, body mass index; CCI, Charlson comorbidity index; CLBP, chronic low back pain; SD, standard deviation.

medications for pain, primarily nonsteroidal anti-inflammatory drugs ( $68 \%$ of those using a prescription).

\section{Bivariate correlations}

Increasing severity of pain in the past week was correlated with worse outcomes (Table 3). More pain was associated with lower HRQoL, with correlations ranging from $r_{\mathrm{s}}=-0.25$ to -0.47 . Those with greater pain also had greater levels of depression and anxiety. Employed respondents' impairment at work was highly correlated with the level of pain, with pain level accounting for $27 \%$ of the variance in overall work impairment $\left(r_{\mathrm{s}}=0.52\right)$. Likewise, more pain was associated with greater activity impairment $\left(r_{\mathrm{s}}=0.52\right)$. HCP and ER visits were related to severity of pain, though the relationship was not strong. Hospitalizations were not related to severity of pain.

\section{Regression analysis}

Almost all the relationships between increasing severity of pain and worse outcomes remained significant after taking into account covariates (Table 4). A change in pain from the 
Table 2 Pain characteristics

\begin{tabular}{ll}
\hline & $\begin{array}{l}\text { Diagnosed CLBP } \\
(\mathbf{N}=\mathbf{2 9 0})\end{array}$ \\
\hline $\begin{array}{l}\text { Severity of LBP } \\
\text { Mild (\%) }\end{array}$ & $78(26.90)$ \\
Moderate (\%) & $161(55.52)$ \\
Severe (\%) & $51(17.59)$ \\
Severity of pain in the past week (0-I0) & $4.92 \pm 2.45$ \\
(mean \pm SD) & \\
Current severity of pain (0-10) (mean \pm SD) & $5.20 \pm 2.31$ \\
Frequency of problems with pain & \\
Once a month or less often (\%) & $12(4.14)$ \\
2-3 times a month (\%) & $28(9.66)$ \\
Once a week (\%) & $31(10.69)$ \\
2-3 times a week (\%) & $59(20.34)$ \\
4-6 times a week (\%) & $25(8.62)$ \\
Daily (\%) & $135(46.55)$ \\
Type of diagnosing doctor for LBP & \\
Orthopedist (\%) & $246(84.83)$ \\
General internist (\%) & $18(6.21)$ \\
Pain management specialist (\%) & $3(1.03)$ \\
Rheumatologist (\%) & $1(0.34)$ \\
Other (\%) & $22(7.59)$ \\
Duration of LBP (in months) (mean \pm SD) & $115 \pm 122$ \\
Current use of a prescription medication for pain (\%) & $120(41.38)$ \\
NSAIDs (\%) & $82(68.33)$ \\
Opioid (\%) & $18(15.00)$ \\
Pregabalin (\%) & $10(8.33)$ \\
Antidepressant (\%) & $3(2.50)$ \\
Other (\%) & $25(20.83)$ \\
Use of an OTC product for pain (\%) & $76(26.21)$ \\
\hline Abbreviations: CLBP, chronic low back pain; LBP, & low back pain, NSAIDs, \\
nonsteroidal anti-inflammatory drugs; OTC, over-the-counter; SD, standard \\
deviation. \\
\end{tabular}

Table 3 Spearman correlation coefficients between pain in the past week and outcomes

\begin{tabular}{lll}
\hline & $\boldsymbol{r}_{\mathrm{s}}$ & $\boldsymbol{P}$-value \\
\hline MCS & -0.25 & $<0.000$ I \\
PCS & -0.47 & $<0.000$ I \\
Health utility score (SF-6D) & -0.38 & $<0.000$ I \\
Depression severity (PHQ-9) & 0.26 & $<0.000$ I \\
Anxiety severity (GAD-7) & 0.23 & $<0.000$ I \\
Absenteeism \% ( $=155)$ & 0.32 & $<0.000$ I \\
Presenteeism \% ( $=155)$ & $0.5 \mathrm{I}$ & $<0.000$ I \\
Overall work impairment \% ( $=155)$ & 0.52 & $<0.000$ I \\
Activity impairment \% & 0.52 & $<0.000$ I \\
HCP visits in the past 6 months & 0.23 & $<0.000$ I \\
ER visits in the past 6 months & 0.12 & 0.035 \\
Hospitalizations in the past 6 months & 0.02 & 0.714 \\
\hline
\end{tabular}

Abbreviations: ER, emergency room; GAD-7, Generalized Anxiety Disorder-7; $\mathrm{HCP}$, health care provider; MCS, mental component summary; PCS, physical component summary; PHQ-9, Patient Health Questionaire-9; SF-6D, ShortForm 6D.

25 th to the 75 th percentile level of pain was associated with a 3.9-point drop in MCS, a 5.5-point drop in PCS, and a 0.07point drop in health utility. The differences in depression and anxiety were modest in size but statistically significant.

Among employed respondents, the same increase in pain was associated with a 5\% absolute increase in absenteeism, a $25 \%$ absolute increase in presenteeism, and a $29 \%$ absolute increase in overall work impairment. The level of impairment to nonwork activities at the 75 th percentile level of pain was more than double that of the 25 th percentile level.

Table 4 Regression-adjusted outcomes according to the level of pain in the past week

\begin{tabular}{|c|c|c|c|c|c|}
\hline \multirow[t]{2}{*}{ Dependent variable } & \multirow{2}{*}{$\begin{array}{l}\text { Patients in } \\
\text { regression } \\
\text { analysis }\end{array}$} & \multirow{2}{*}{$\begin{array}{l}\text { P-value for } \\
\text { pain in the } \\
\text { past week }\end{array}$} & \multicolumn{3}{|c|}{$\begin{array}{l}\text { Regression-estimated outcome values at levels of pain in the } \\
\text { past week }\end{array}$} \\
\hline & & & $\begin{array}{l}\text { At } 25 \text { th percentile } \\
(3 / 10) ; \text { mild }\end{array}$ & $\begin{array}{l}\text { At median }(5 / 10) \text {; } \\
\text { moderate }\end{array}$ & $\begin{array}{l}\text { At } 75 \text { th percentile } \\
(7 / 10) \text {; severe }\end{array}$ \\
\hline MCS & 290 & $<0.001$ & 47.1 & 45.1 & 43.2 \\
\hline PCS & 290 & $<0.001$ & 48.5 & 45.7 & 43.0 \\
\hline Health utility score (SF-6D) & 290 & $<0.001$ & 0.70 & 0.67 & 0.63 \\
\hline Depression severity (PHQ-9) & 290 & $<0.001$ & 3.3 & 4.1 & 5.3 \\
\hline Anxiety severity (GAD-7) & 290 & $<0.001$ & 3.2 & 3.8 & 4.7 \\
\hline Absenteeism & 155 & 0.003 & $0.7 \%$ & $2.0 \%$ & $5.8 \%$ \\
\hline Presenteeism & 155 & $<0.00$ I & $17.8 \%$ & $27.6 \%$ & $42.9 \%$ \\
\hline Overall work impairment & 155 & $<0.001$ & $19.2 \%$ & $30.5 \%$ & $48.4 \%$ \\
\hline Activity impairment & 290 & $<0.001$ & $22.0 \%$ & $31.7 \%$ & $45.7 \%$ \\
\hline $\mathrm{HCP}$ visits in the past 6 months & 290 & 0.007 & 10.4 & 12.1 & 13.9 \\
\hline ER visits in the past 6 months & 290 & 0.189 & 0.05 & 0.07 & 0.11 \\
\hline Hospitalizations in the past 6 months & 290 & 0.705 & 0.21 & 0.25 & 0.29 \\
\hline
\end{tabular}

Notes: Values are presented at the mean of the covariates. Covariates included duration of CLBP, age, sex, Charlson comorbidity index, annual household income, marital status, completion of a university degree, body mass index category, smoking status, alcohol use, and exercise in the prior month.

Abbreviations: CLBP, chronic low back pain; ER, emergency room; GAD-7, Generalized Anxiety Disorder-7; HCP, health care provider; MCS, mental component summary; PCS, physical component summary; PHQ-9, Patient Health Questionaire-9; SF-6D, Short-Form 6D. 
As pain is reduced from the 75 th percentile level to the 25 th percentile, the number of HCP visits during a 6-month period was reduced by 3.5 , though no differences were observed in emergency department visits or hospitalizations.

\section{Discussion}

The current study revealed significant relationships between the severity of pain among patients with CLBP and a range of health outcomes relating to HRQoL in terms of both physical and mental health outcomes, work productivity, activity impairment, and use of health care resources among Japanese adults. As pain severity increased from the first quartile (3/10) to the third (7/10), the differences observed in HRQoL surpassed the minimally important differences for these measures, which are 3 points for the MCS and PCS scores, ${ }^{17}$ and 0.03 points for the SF-6D index. ${ }^{23}$ This demonstrates that meaningful decreases in HRQoL are associated with increasing pain severity among patients with CLBP and builds on earlier research conducted in five medical centers that estimated that diagnosed LBP (not necessarily chronic) led to a loss of 947,000 quality-adjusted life years in Japan. ${ }^{24}$

Severity of pain was also associated with increased levels of anxiety and depression among these patients, consistent with other evidence indicating that psychological issues can be associated with the manifestations and progression of CLBP. ${ }^{24}$ As pain becomes more severe, patients may need greater support addressing the psychological effects of the condition, in addition to the physical effects.

Furthermore, higher severity of pain was correlated with impairment in both nonwork activities and worker productivity, demonstrating the far-ranging effects of pain on various aspects of daily life. As the intensity of pain increased from $3 / 10$ to $7 / 10$ on the NRS, both nonwork activity impairment and overall work impairment more than doubled. This is in line with other research that found more patients with severe CLBP had to switch their job roles compared with patients who had lower pain severity. ${ }^{9}$ The increase in overall work impairment among NHWS respondents was mainly due to higher rates of presenteeism, though absenteeism also rose $\sim 5 \%$, which would equate to $\sim 2$ hours per worker per 40 -hour workweek. Although interventions that support timely work return and reduce productivity loss for patients with CLBP could result in considerable cost savings ${ }^{25}$ targeting individuals who have the most severe pain levels might offer the greatest savings. These results also demonstrate an opportunity for employers to offer worksite wellness programs that treat CLBP and ensure that those diagnosed with CLBP do not progress in their pain severity levels.
Health care use also increased with pain severity. Pain at the 75th percentile was associated with approximately seven additional HCP visits per year. This is consistent with findings from studies in other countries that assessed use of outpatient care and found that direct medical costs increased proportionately with worsening pain severity among patients with CLBP. ${ }^{11,12}$ Ensuring individuals who experience LBP are offered appropriate treatment and support in an effort to reduce or at least halt the progression of their pain may help contain such costs. The number of ER visits and the number of hospital admissions were not significantly related to pain severity; however, the sample size of the current study was too small to detect relationships between severity and relatively rare events such as these. Overall, the current study provides further evidence of increased health care use and contributes to existing literature indicating increased direct medical costs among these patients. ${ }^{11,12}$

\section{Limitations}

This analysis does have potential limitations. Although other studies found that severity of CLBP was associated with significant medication use, ${ }^{7}$ this study did not look at medication costs or the charges associated with health care resource use, only the resource use itself. The analysis was based on an Internet survey, which may limit the findings' generalizability by including only the study respondents who use the Internet and computers. Another limitation is the use of patient-reported data, particularly with measures of physical functioning. Research suggests that patients with CLBP may be more likely to underestimate their activity, ${ }^{26}$ so future research should confirm the relationship with measures of activity limitation that do not rely on self-report.

Additionally, in order to be included in the current analysis, respondents had to identify pain as one of the medical conditions they experienced in the prior 12 months. This may have resulted in the identification of fewer patients than if all respondents to the NHWS had been asked their level of pain without having to identify pain as a medical condition that they experienced and may partially account for the disparity between the prevalence in previous survey results and those reported here. Part of the disparity is also likely due to the numerous exclusion criteria adopted here in order to ensure other pain was not misattributed to CLBP, particularly other types and sites of pain. Indeed, 2,226 of the 29,997 respondents (7.4\%) reported experiencing LBP in the past month, but most were excluded for lack of diagnosis or comorbidities. However, focusing on respondents with relatively pure CLBP allows the current study to demonstrate 
the relationship between pain severity and outcomes with the fewest potential confounders.

\section{Conclusion}

This study provides a valuable addition to the literature by examining the relationship between the severity of pain and a range of outcomes specifically among patients with CLBP in Japan, which has been understudied relative to other areas of the world. Our results demonstrate that more severe pain among patients with CLBP is significantly related to reduced physical functioning, mental health, worker productivity, and increased health care use in Japan. This underscores the importance of not only targeting and treating back pain but also assessing patients' severity levels in order to develop effective treatments and interventions. Due to the impact of CLBP on HRQoL, health care use, worker productivity, and daily activities, we suggest that patients, insurers, and employers can all benefit from better treatment and management strategies addressing this condition. ${ }^{11}$

\section{Acknowledgments}

Funding for this study was provided to Kantar Health by Eli Lilly Japan K.K.

\section{Disclosure}

William Montgomery is an employee of Eli Lilly Australia Pty Ltd. Sawako Kariyasu, Kei Ogawa, and Levent Alev are employees of Eli Lilly Japan K.K. Jeffrey Vietri is an employee of Kantar Health. Jing Shi was an employee of Kantar Health during the conduct of the study. Masaya Nakamura has received speaking fees from Eli Lilly Japan K.K. Sara Bodnar provided writing assistance funded by Kantar Health. The authors report no other conflicts of interest in this work.

\section{References}

1. Choi YS, Kim DJ, Lee KY, et al. How does chronic back pain influence quality of life in Koreans : a cross-sectional study. Asian Spine J. 2014;8(3):346-352.

2. Bouhassira D, Lantéri-Minet M, Attal N, Laurent B, Touboul C. Prevalence of chronic pain with neuropathic characteristics in the general population. Pain. 2008;136(3):380-387.

3. Davis JA, Robsinson RL, Le TK, Xie J. Incidence and impact of pain conditions and comorbid illnesses. J Pain Res. 2011;4:331-345.

4. Fujii T, Matsudaira K, Oka H. The association between compensation and chronic disabling back pain. J Orthop Sci. 2012;17(6):694-698.

5. Nakamura M, Nishiwaki Y, Ushida T, Toyama Y. Prevalence and characteristics of chronic musculoskeletal pain in Japan. J Orthop Sci. 2011;16(4):424-432.
6. Takura T, Ushida T, Kanchiku T, et al. The societal burden of chronic pain in Japan: an internet survey. J Orthop Sci. 2015;20(4):750-760.

7. Taylor-Stokes G, Lobosco S, Pike J, Sadosky AB, Ross E. Relationship between patient-reported chronic low back pain severity and medication resources. Clin Ther. 2011;33(11):1739-1748.

8. Gore M, Sadosky A, Stacey BR, Tai KS, Leslie D. The burden of chronic low back pain. Spine (Phila Pa 1976). 2012;37(11):E668-E677.

9. Sadosky AB, Taylor-Stokes G, Lobosco S, Pike J, Ross E. Relationship between self-reported low-back pain severity and other patient-reported outcomes. J Spinal Disord Tech. 2013;26(1):8-14.

10. McDonald M, DiBonaventura Md, Ullman S. Musculoskeletal pain in the workforce: the effects of back, arthritis, and fibromyalgia pain on quality of life and work productivity. J Occup Environ Med. 2011;53(7):765-770.

11. Ekman M, Jönhagen S, Hunsche E, Jönsson L. Burden of illness of chronic low back pain in Sweden: a cross-sectional, retrospective study in primary care setting. Spine (Phila Pa 1976). 2005;30(15):1777-1785.

12. Depont F, Hunsche E, Abouelfath A, et al. Medical and non-medical direct costs of chronic low back pain in patients consulting primary care physicians in France. Fundam Clin Pharmacol. 2010;24(1):101-108.

13. Sadosky AB, Bushmakin AG, Cappelleri JC, Lionberger DR. Relationship between patient-reported disease severity in osteoarthritis and self-reported pain, function and work productivity. Arthritis Res Ther. 2010;12(4):R162.

14. Schaefer C, Sadosky A, Mann R, et al. Pain severity and the economic burden of neuropathic pain in the United States: BEAT Neuropathic Pain Observational Study. Clinicoecon Outcomes Res. 2014;6:483-496.

15. Taylor-Stokes G, Pike J, Sadosky A, Chandran A, Toelle T. Association of patient-rated severity with other outcomes in patients with painful diabetic peripheral neuropathy. Diabetes Metab Syndr Obes. 2011;4:401-408.

16. Nakamura M, Nishiwaki Y, Ushida T, Toyama Y. Prevalence and characteristics of chronic musculoskeletal pain in Japan: a second survey of people with or without chronic pain. J Orthop Sci. 2014; 19(2):339-350.

17. Maruish ME. User's Manual for the SF-36v2 Health Survey. 3rd ed. Lincoln, Rhode Island: Quality Metric Incorporated; 2011.

18. Brazier JE, Roberts J. The estimation of a preference-based measure of health from the SF-12. Med Care. 2004;42(9):851-859.

19. Kroenke K, Spitzer RL, Williams JB. The PHQ-9: validity of a brief depression severity measure. J Gen Intern Med. 2001;16(9):606-613.

20. Spitzer RL, Kroenke K, Williams JB, Löwe B. A brief measure for assessing generalized anxiety disorder: the GAD-7. Arch Intern Med. 2006;166(10):1092-1097.

21. Reilly MC, Zbrozek AS, Dukes EM. The validity and reproducibility of a work productivity and activity impairment instrument. Pharmacoeconomics. 1993;4(5):353-365.

22. Charlson M, Szatrowski TP, Peterson J, Gold J. Validation of a combined comorbidity index. J Clin Epidemiol. 1994;47(11):1245-1251.

23. Walters SJ, Brazier JE. What is the relationship between the minimally important difference and health state utility values? The case of the SF-6D. Health Qual Life Outcomes. 2003;1:4.

24. Suka M, Yoshida K. Low back pain deprives the Japanese adult population of their quality of life: a questionnaire survey at five healthcare facilities in Japan. Environ Health Prev Med. 2008;13(2):109-115.

25. Dagenais S, Caro J, Haldeman S. A systematic review of low back pain cost of illness studies in the United States and internationally. Spine J. 2008;8(1):8-20.

26. van Weering MG, Vollenbroek-Hutten MM, Hermens HJ. The relationship between objectively and subjectively measured activity levels in people with chronic low back pain. Clin Rehabil. 2011; 25(3):256-263. 
Journal of Pain Research

\section{Publish your work in this journal}

The Journal of Pain Research is an international, peer-reviewed, open access, online journal that welcomes laboratory and clinical findings in the fields of pain research and the prevention and management of pain. Original research, reviews, symposium reports, hypothesis formation and commentaries are all considered for publication.

The manuscript management system is completely online and includes a very quick and fair peer-review system, which is all easy to use. Visit http://www.dovepress.com/testimonials.php to read real quotes from published authors.

\footnotetext{
Submit your manuscript here: http://www.dovepress.com/journal-of-pain-research-journal
} 